\title{
Contemporary management of primary parapharyngeal space tumors
}

Fernando López MD, PhD, FEBORL-HNS ${ }^{1,2}$ @ । Carlos Suárez MD, $\mathrm{PhD}^{2}$ ।

Vincent Vander Poorten $\mathrm{MD}^{3,4}$ @ । Antti Mäkitie MD, $\mathrm{PhD}^{5}$ ।

Iain J. Nixon MD, MBChB, FRCS (ORL-HNS), $\mathrm{PhD}^{6}$ । Primož Strojan $\mathrm{MD}, \mathrm{PhD}^{7}$ @ ।

Ehab Y. Hanna $\mathrm{MD}^{8}$ @ । Juan Pablo Rodrigo MD, $\mathrm{PhD}^{1,2}$ (ㅇ । Remco de Bree MD, $\mathrm{PhD}^{9}$ @ ।

Miquel Quer MD, $\mathrm{PhD}^{10}$ । Robert P. Takes MD, $\mathrm{PhD}^{11}$ @ । Carol R. Bradford $\mathrm{MD}^{12}$ ।

Ashok R. Shaha $\mathrm{MD}^{13}$ । Alvaro Sanabria MSc, $\mathrm{PhD}^{14}$ ।

Alessandra Rinaldo MD, FRCS Ed ad hominem, FRCS (Eng, Ir) ad eundem, FRCSGlasg ${ }^{15}$ ।

Alfio Ferlito MD, DLO, DPath, FRCSEd ad hominem, FRCS (Eng, Glasg, Ir) ad eundem, FDSRCS ad eundem, FHKCORL, FRCPath, FASCP, IFCAP ${ }^{16} \odot$

\footnotetext{
${ }^{1}$ Department of Otolaryngology, Hospital Universitario Central de Asturias, Oviedo, Spain

${ }^{2}$ Instituto de Investigación Sanitaria del Principado de Asturias, Instituto Universitario de Oncología del Principado de Asturias, University of Oviedo, CIBERONC, Oviedo, Spain

${ }^{3}$ Department of Otorhinolaryngology-Head and Neck Surgery, University Hospitals Leuven, Leuven, Belgium

${ }^{4}$ Department of Oncology, Section Head and Neck Oncology, University Hospitals Leuven, Leuven, Belgium

${ }^{5}$ Department of Otorhinolaryngology, Head and Neck Surgery, Helsinki University Hospital, University of Helsinki, Helsinki, Finland

${ }^{6} \mathrm{NHS}$ Lothian, University of Edinburgh, Edinburgh, United Kingdom

${ }^{7}$ Department of Radiation Oncology, Institute of Oncology, Ljubljana, Slovenia

${ }^{8}$ Department of Head and Neck Surgery, The University of Texas MD Anderson Cancer Center, Houston, Texas

${ }^{9}$ Department of Head and Neck Surgical Oncology, University Medical Center Utrecht, Utrecht, The Netherlands

${ }^{10}$ Department of Otolaryngology, Hospital Santa Creu i Sant Pau, Barcelona, Spain

${ }^{11}$ Department of Otolaryngology-Head and Neck Surgery, Radboud University Medical Center, Nijmegen, The Netherlands

${ }^{12}$ Department of Otolaryngology-Head and Neck Surgery, University of Michigan, Ann Arbor, Michigan

${ }^{13}$ Head and Neck Service, Memorial Sloan-Kettering Cancer Center, New York, New York

${ }^{14}$ Department of Surgery, School of Medicine, Universidad de Antioquia, Clínica Vida/Instituto de Cancerología Las Américas, Medellín, Colombia

${ }^{15}$ University of Udine School of Medicine, Udine, Italy

${ }^{16}$ Coordinator of the International Head and Neck Scientific Group
}

\section{Correspondence}

Fernando López, Department of Otolaryngology, Hospital Universitario Central de Asturias, Avenida de Roma s/n, 33011 Oviedo (Asturias), Spain.

Email: flopez_1981@yahoo.es

\begin{abstract}
The parapharyngeal space is a complex anatomical area. Primary parapharyngeal tumors are rare tumors and $80 \%$ of them are benign. A variety of tumor types can develop in this location; most common are salivary gland neoplasm and neurogenic tumors. The management of these tumors has improved greatly owing to the developments in imaging techniques, surgery, and radiotherapy. Most tumors can be removed with a low rate of complications and recurrence. The transcervical approach is the most frequently used. In some cases, minimally invasive
\end{abstract}

This article was written by members of the International Head and Neck Scientific Group (www.IHNSG.com).

Ehab Y. Hanna, MD, Editor, was recused from consideration of this manuscript. 
approaches may be used alone or in combination with a limited transcervical route, allowing large tumors to be removed by reducing morbidity of expanded approaches. An adequate knowledge of the anatomy and a careful surgical plan is essential to tailor management according to the patient and the tumor. The purpose of the present review was to update current aspects of knowledge related to this more challenging area of tumor occurrence.

\section{KEYWORDS}

paraganglioma, parapharyngeal tumors, pleomorphic adenoma, schwannoma, transcervical approach

\section{1 | INTRODUCTION}

Parapharyngeal space (PPS) tumors form a heterogeneous group of lesions arising in an anatomically complex region, which is challenging to examine clinically due to its deep neck location lateral to the pharynx and medial to the jaw. These lesions are uncommon accounting for approximately $0.5 \%$ of all head and neck tumors. ${ }^{1}$ Salivary gland tumors are the most common, followed by neurogenic neoplasms. ${ }^{2}$ Most lesions in this region are benign (80\%), and surgical excision is the standard primary treatment. ${ }^{2-4}$ To provide adequate preoperative counseling and to reduce patient morbidity, the surgeon must have a thorough understanding of treatment of these tumors.

The diagnostics and management of PPS tumors form a challenge because of their low occurrence rate, anatomical relationships, and histological diversity. The relevant literature on PPS tumors is growing but is still limited to rather small case series. Several systematic reviews have recently been published, focusing on the frequency of the various histological subtypes and surgical approaches used., ${ }^{2,3,5}$ This article reviews the anatomy, pathology, clinical and radiologic evaluation, and surgical treatment of primary PPS tumors, highlighting new surgical approaches and nonsurgical treatment.

\section{2 | ANATOMY}

PPS is located in the suprahyoid neck with a shape resembling an inverted pyramid with the floor at the skull base and its tip at the greater horn of the hyoid bone. ${ }^{6}$ The superior limit of the PPS is a small portion of the petrous portion of the temporal bone and the sphenoid bone. It includes the carotid canal, the jugular foramen, and the hypoglossal foramen. Laterally, there is a fascial connection from the medial pterygoid plate to the spine of the sphenoid, which crosses medial to the foramen ovale and foramen spinosum, which are not included in this space but are rather located in the infratemporal fossa. ${ }^{7}$ The inferior boundary is the junction of the posterior belly of the digastric muscle and the greater cornu of the hyoid bone. The PPS is blended into the posterior aspect of submandibular space on this level. Medially, the boundary consists of the buccopharyngeal or visceral fascia overlying the pharyngobasilar fascia and pharyngeal constrictors muscles. The lateral boundary includes the fascia over the medial pterygoid muscle, the ramus of the mandible, the posterior belly of the digastric muscle, and the fascia over the retromandibular deep portion of the parotid gland. Anteriorly, the limit is the pterygomandibular raphe. The posterior limit is the dorsal layer of fascia making up the carotid sheath. The internal carotid artery (ICA), internal jugular vein (IJV), cranial nerves IX-XII, and sympathetic chain all course through this space.

A key anatomical division of the PPS is into prestyloid and retrostyloid compartments, facilitating differential diagnosis of PPS lesions. Fascia runs posteriorly from the styloid process to the tensor veli palatini muscle, called the tensorvascular-styloid fascia, because it also contains the ascending palatine artery and vein, divides the PPS into an anterolateral or prestyloid and a posteromedial, or retrostyloid compartments. Assessment can be made on imaging based upon displacement of the PPS fat, with posteriorly based tumors displacing fat anteriorly and anterior tumors displacing fat posteriorly. ${ }^{8}$ The prestyloid compartment contains fat, a portion of the retromandibular parotid gland, and some lymph nodes. The retrostyloid compartment contains the ICA, IJV, lower cranial nerves (IX-XII), sympathetic chain, and lymph nodes. PPS tumors may arise from each of these structures, which are at risk during surgery. The PPS contains numerous lymphatics, which along with the retropharyngeal nodes drain the soft palate, paranasal sinuses, posterior oral cavity, base of tongue, and a portion of the thyroid gland. The parapharyngeal nodes superiorly are connected to the node of Rouvière in the lateral most retropharyngeal space; this can be a site of metastasis from the nasopharynx, upper oropharynx, and paranasal sinuses.

The stylomandibular tunnel is bounded by the posterior ramus of the mandible, the skull base, and the stylomandibular ligament. Deep lobe parotid tumors can extend into the 
prestyloid PPS posterior to the stylomandibular ligament resulting in a "dumbbell"-shaped mass. ${ }^{6}$

Prasad et $\mathrm{al}^{9}$ have proposed that the PPS could be divided into three alternative compartments with diagnostic and surgical implications: the upper, the middle, and lower part. The inferior border of the lateral pterygoid muscle divides the upper and middle portions, while an imaginary line joining the angles of the jaw on both sides separates the middle from the lower. This compartmentalization parallels the best surgical approach for each tumor.

\section{3 | PATHOLOGY}

According to a systematic review by Riffat et $a{ }^{2},{ }^{2}$ tumors from up to 70 histological subtypes can be identified in the PPS (Table 1). Approximately $80 \%$ of these tumors are benign and $20 \%$ malignant. ${ }^{2,5}$ Prestyloid tumors are more common $(59 \%)$ than retrostyloid ones $(26 \%)$; although, in some cases, it is difficult to determine the exact origin of the tumor (prestyloid/retrostyloid) (15\%). ${ }^{14}$ PPS tumors can be grouped into three categories: primary, extension from adjacent structures, and metastatic.

Primary PPS neoplasms, the subject of this review, fall into three main categories: salivary gland neoplasms (prestyloid) (45\%), neurogenic tumors (retrostyloid) (45\%), and miscellaneous tumors $(10 \%){ }^{2}$ Moreover, direct extension of tumors into the PPS can occur from the mandible, maxilla, nasopharynx, neck, oral cavity, oropharynx, and temporal bone. It is important to note that some series of PPS tumors include all deep lobe parotid tumors, lesions originating at the foramen ovale, and carotid body paragangliomas. These cases should be excluded and only tumors that affect at least the retromandibular part of the deep lobe of the parotid and carotid body paragangliomas localized above the posterior belly of the digastric should be considered PPS tumors. Lesions arising at the foramen ovale should be considered as infratemporal fossa tumors. Metastatic tumors to Rouvières nodes (less than 5\%) include thyroid gland carcinomas, squamous cell carcinomas, including nasopharyngeal type, esthesioneuroblastomas, sarcomas, and other unspecified lesions.

\section{4 | SALIVARY GLAND TUMORS}

Salivary gland tumors are the most common PPS tumors accounting for $40 \%-50 \%$ of cases, ${ }^{2,15,16}$ although in some series, neurogenic tumors are reported more frequently. ${ }^{10}$ These tumors are located in the prestyloid space and can arise from either the deep lobe of the parotid gland (less than $5 \%$ of parotid tumors involve the PPS) or from minor salivary glands. A fat plane on CT or MRI between the mass and the parotid helps distinguish a tumor of minor salivary origin from a deep lobe parotid tumor. Unfortunately, in
TABLE 1 Histopathological diagnosis of the most frequent PPS tumors ${ }^{\mathrm{a}}$

\begin{tabular}{|c|c|}
\hline Pathology & Frequency \\
\hline Salivary tumors & $45 \%$ \\
\hline - Benign & $80 \%$ \\
\hline - Pleomorphic adenoma & $50 \%$ \\
\hline - Other benign ${ }^{\mathrm{b}}$ & $30 \%$ \\
\hline - Malignant & $20 \%$ \\
\hline - Adenoid cystic carcinoma & $9 \%$ \\
\hline - Mucoepidermoid carcinoma & $5 \%$ \\
\hline - Carcinoma ex-pleomorphic adenoma & $1 \%$ \\
\hline - Squamous cell carcinoma & $1 \%$ \\
\hline - Adenocarcinoma & $1 \%$ \\
\hline - Myoepithelial carcioma & $1 \%$ \\
\hline - Neurogenic lesions & $1 \%$ \\
\hline - Other malignant ${ }^{\mathrm{c}}$ & $1 \%$ \\
\hline Neurogenic tumors & $45 \%$ \\
\hline - Benign & $95 \%$ \\
\hline - Vagal paraganglioma & $35 \%$ \\
\hline - Schwannoma & $50 \%$ \\
\hline - Neurofibroma & $5 \%$ \\
\hline - Sympathetic paraganglioma & $1 \%$ \\
\hline - Other benign & $4 \%$ \\
\hline - Malignant & $5 \%$ \\
\hline - Malignant PNST & $1 \%$ \\
\hline - Malignant paraganglioma & $1 \%$ \\
\hline - Other unspecified malignant lesions & $3 \%$ \\
\hline Miscellaneous & $10 \%$ \\
\hline - Benign & $70 \%$ \\
\hline - Branchial cleft cyst & $10 \%$ \\
\hline - Arteriovenous malformations & $1 \%$ \\
\hline - Other ${ }^{\mathrm{d}}$ & $59 \%$ \\
\hline - Malignant & $30 \%$ \\
\hline - Chondrosarcoma & $1 \%$ \\
\hline - Rhabdomyosarcoma & $1 \%$ \\
\hline - Undifferentiated carcinoma & $1 \%$ \\
\hline - Lymphoid lesions & $1 \%$ \\
\hline - Other unspecified malignant lesions & $26 \%$ \\
\hline \multicolumn{2}{|c|}{$\begin{array}{l}\text { a These global data come from recent studies of patients with PPS } \\
\text { tumors. }{ }^{2,3,5,10-13} \text { Different proportions can be found in some series. } \\
\text { b Other benign salivary tumors include Warthin's tumor, basal cell adenoma, } \\
\text { myoephitelioma, monomorphic adenoma, lymphoepitelial lesion, granuloma- } \\
\text { tous parotitis, and other unspecified lesions. } \\
\text { c Other malignant salivary tumors include acinic cell carcinoma, undifferentiated } \\
\text { carcinoma, and other unspecified lesions. } \\
\text { d Other benign miscellaneous lesions include meningiomas, cystic higroma, } \\
\text { aneurysm, lymphangioma, leiomyoma, lipoma, osteolipoma, fibromatosis, des- } \\
\text { moid tumor, fibromyxoma, fibrous tumor, cysts, inflammatory pseudotumor, } \\
\text { and other unspecified lesions. }\end{array}$} \\
\hline
\end{tabular}

clinical practice, it is not always clear if this fat plane is intact over the whole surface between parotid gland and tumor, making discrimination between parotid and minor salivary gland tumors difficult.

More than 15 different histological types of salivary gland tumors have been reported in the PPS. ${ }^{2}$ The vast majority $(80 \%)$ of these salivary lesions are benign. Pleomorphic adenoma is the commonest PPS tumor (up to $30 \%$ 
of PPS lesions and $60 \%$ of salivary gland tumors). Malignant tumors account for a $20 \%$ of all salivary gland tumors, with adenoid cystic (less than 10\%) and mucoepidermoid carcinoma (less than $5 \%$ ) being the most common ones. ${ }^{2}$

\section{5 | NEUROGENIC TUMORS}

Neurogenic tumors account for $40 \%$ of PPS neoplasms and are grouped into three main histological subtypes: paragangliomas, schwannomas, and neurofibromas. ${ }^{2}$ The vast majority of neurogenic tumors (95\%) are benign. Depending on the reported series, either paragangliomas ${ }^{2}$ or schwannomas ${ }^{17,18}$ is the most frequent histological subtypes. Although paragangliomas are not strictly neurogenic tumors as they arise from paraganglia, in most series, they are included in this category, because they may intimately be associated with cranial nerves, such as jugular paragangliomas, which do not arise in nervous structures but can expand to include nerves. For this reason, we have included them in this group. Malignant peripheral nerve sheath tumors (PNSTs) are the most common malignant neurogenic lesions. ${ }^{2}$

The most common PPS paragangliomas arise from the vagus nerve ( $\mathrm{CN} \mathrm{X)}$ (retrostyloid). Multiple paragangliomas may occur synchronously or metachronously. Multicentric tumors occur in $10 \%-20 \%$ of all head and neck paragangliomas. However, reports of much higher incidence of multiple tumors, like $40 \%$ for sporadic form and $80 \%$ for familial variety, can be found. Bilateral tumors have been reported in up to $10 \%$ of sporadic cases and $30 \%$ of hereditary cases. These tumors can secrete catecholamines $2 \%$ of the time, causing hypertension and flushing. This is an important perioperative consideration, and patients with these symptoms should have a 24-hour urine collection evaluated for catecholamines, vanillylmandelic acid, and metanephrines. ${ }^{19}$ Perioperative beta blockade may be indicated in patients with secreting tumors. The genetics of these hereditary tumors are related to mutations of the succinate dehydrogenase (SDH) genes. Genetic testing of patients with a positive family history and/or multiple tumors is recommended. Malignancies have been reported in 6\%-19\%. The malignant nature is demonstrated by imaging studies that reveal regional or distant metastasis. As the presence of lymph node metastases may be the only sign of malignancy, it is recommended that lymph nodes be removed during resections of these tumors, especially in cases of vagal paragangliomas and those carriers of the $S D H B$ mutation, in which the rate of malignancy is slightly higher. For paragangliomas that occur in the neck, levels II and III are easily addressed and samples should be taken. In cases of preoperative lymph node involvement by paraganglioma, modified neck dissection is indicated. It should minimally address levels II to IV. Histologically, the difference between benign and malignant paragangliomas cannot be made. ${ }^{20}$
Schwannomas are retrostyloid lesions. The most common site of origin is the vagus nerve (CN X), while the sympathetic chain is the second. Nevertheless, tumors originating from cranial nerves IX, XI, and XII have been also described. They usually do not cause functional impairment of their nerve of origin, but as they enlarge, they can present as a mass and affect the function of adjacent nerves. These lesions can extend up through the jugular foramen intracranially. Less than $1 \%$ will undergo malignant transformation. Treatment requires enucleation and, although postoperative neurological deficit of the nerve involved is almost always inevitable, it is sometimes possible to preserve the nerve involved, particularly when capsule is opened via a vertical incision minimizing the risk of injury of the nerve fibers running into the periphery of the tumor and use of intraoperative nerve monitoring for vagal schwannomas using an endotracheal tube monitoring device for vocal-fold motion response. ${ }^{21}$

Neurofibromas may also occur as retrostyloid lesions. They originate from the Schwann cells and perineural fibroblasts. These tumors are unencapsulated and intimate involvement of the nerve of origin is common. Sites of origin include the vagal nerve, glossopharyngeal nerve (IX), sympathetic chain, and spinal accessory nerve (XI). These lesions are often multiple and can be associated with neurofibromatosis type I, in which case there is a higher incidence of malignancy. Removal of these tumors usually involves sacrificing the nerve from which it arises.

\section{6 | MISCELLANEOUS TUMORS}

A wide variety of more than 40 different types of benign (70\%) and malignant (30\%) neoplasms can occur in the PPS and account for $10 \%$ of lesions. ${ }^{2}$ A comprehensive list is beyond the scope of this review but may be grouped into soft tissue tumors, bone tumors, and inflammatory tumors. Some possible masses include ICA aneurysms, branchial cleft cysts, hemangiomas, lymphogenic malformations, arteriovenous malformations, meningiomas, teratomas, and lipomas. Lymphomas are the commonest malignant lesions in this group.

\section{7 | CLINICAL EVALUATION}

The signs and symptoms of PPS neoplasms can be subtle and clinical evaluation of this space is difficult. A significantly number of patients have asymptomatic growth for a long period, and the tumor is detected during a routine checkup or while scanning for other reasons. ${ }^{10}$ In most cases, tumors are slow-growing lesions and symptoms do not appear until the tumor reaches certain dimensions or affects nerve structures, so their diagnosis is usually late. Whereas Sun et $\mathrm{al}^{10}$ reported that $44 \%$ of the patients have 
no symptoms and $23 \%$ of the patients have no clinical signs and that it is a potential challenge for surgeons not to induce or worsen symptoms by the treatment of these tumors.

The most frequent clinical signs and symptoms are a palpable cervical mass or an intraoral swelling, which are present in more than half of the cases. Symptoms related to mass effect of the tumor or neural invasion are also common. ${ }^{2,10}$ These include pain, dysphagia, dysphonia, dyspnea, dysarthria, otalgia, snoring, or foreign body sensation. In paragangliomas, symptoms of catecholamine excess like hypertension and flushing can be present. ${ }^{10}$

All patients should undergo a comprehensive medical history and head and neck examination, including nasopharyngoscopy, audiological and cranial nerve assessment, and airway, speech, and swallowing evaluation. If the lesion is large enough to be palpated, bimanual palpation is important. Tumors must reach a size of $2.5-3 \mathrm{~cm}$ before becoming palpable as a mass because of the deep location in the neck, so they can reach a large size prior to presentation. ${ }^{4,22}$ PPS lesions usually enlarge medially and inferiorly; medial enlargement results in an asymmetric intraoral smooth and submucosal swelling and downward growth manifests as a mass in the neck at the angle of the mandible. ${ }^{23,24}$ Parotid lesions typically distort the tonsil, while neurogenic lesions distort the posterior pharynx and posterior tonsillar pillar. ${ }^{25}$ The presence of a parotid mass in conjunction with an intraoral mass suggests a "dumbbell"-shaped deep lobe parotid tumor.

Tumors expanding into the retrostyloid compartment may compress cranial nerves IX through to XII and the cervical sympathetic chain. The presence of vagal dysfunction with vocal cord palsy and Horner's syndrome are the most frequent nerve disturbances and are a reason for further investigation. Cranial nerve deficits and medial enlargement of masses may lead to symptoms of dysphagia, dysphonia and dyspnea. Superior enlargement of masses can compress the opening of the Eustachian tube (24) leading to unilateral middle ear effusion and its resulting sequelae. ${ }^{25}$

In selective cases, fine needle aspiration cytology (FNAC) of the lesion can be useful if a malignant tumor is suspected, but its widespread use is controversial; this should only be performed after imaging to rule out a vascular lesion. Results with FNAC are variably reported by different authors. ${ }^{26,27}$ Combining FNAC with ultrasound or CT seems to offer more accurate results. ${ }^{2}$ Peroral or transcervical FNAC can reach an accuracy of up to $90 \%-95 \%$, with a higher accuracy in malignant tumors as compared to benign ones. ${ }^{11,28}$ The rate of nondiagnostic FNAC is moderately high (25\%-60\%) as a result of excessive bleeding, lack of cellular material, and other technical problems related to adequately targeting the lesion in close vicinity of major neck vessels. ${ }^{14,29,30}$ Transoral incisional biopsy is to be condemned, be it of lesions of salivary gland origin (because it complicates removal and is associated with tumor spillage) or of paragangliomas (in which the diagnosis with imaging is accurate enough for treatment planning). ${ }^{29,30}$

\section{8 | IMAGING}

Cross-sectional imaging is essential when a parapharyngeal tumor is suspected. ${ }^{7,31} \mathrm{CT}$, MRI, and magnetic resonance (MR) angiography are complementary in the evaluation of the tumor-host interface, neurovascular structures, glandular and soft tissue, and the relationship to the skull base. Both CT and MRI are essential for all types of PPS tumors, particularly those that are extensive, potentially malignant, or in the setting of recurrence. Angiography should be considered for all enhancing lesions, when preoperative embolization is envisaged. If catecholamine levels are positive, a metaiodobenzylguanidine scan should be performed to investigate catecholamine uptake and storage. In cases in which paraganglioma is suspected, somatostatin analog imaging such as ${ }^{32}$ Ga-DOTATATE PET/CT is a functional imaging modality for evaluating these tumors.

Three main issues should be taken into account when evaluating imaging studies: (1) the relationship of the airway with the tumor and its possible involvement during treatment should be assessed in the coronal images; (2) the axial slices allow us to determine its exact location, observe the contrast uptake, and determine its relationship with the parotid and ICA; and (3) in the coronal and sagittal slices, we can observe the relationship of the tumor with the base of the skull. Moreover, there are some characteristics that suggest malignancy such as the invasion of adjacent muscle and fat, bone destruction, irregular tumor margins, obliterated fascial planes, and lymphadenopathy. With combination of information on precise tumor location and imaging characteristics, multidetector-row CT and MR findings could be used for prediction of tumor type. Recently, in group of 84 tumors, an imaging-based histopathological diagnosis was found to be in agreement with the final histological diagnosis in $92 \%$ of the tumors: in all paragangliomas, in $77 \%$ pleomorphic adenomas, and in $90 \%$ of schwannomas. ${ }^{33}$

As a whole, prestyloid tumors displace the ICA posteriorly in CT or MRI and retrostyloid tumors displace the ICA anteromedially (Figures 1 and 2). ${ }^{24}$ This facilitates differentiation between salivary gland tumors and neurogenic tumors. Moreover, it is possible to differentiate whether a schwannomas originates from the vagus nerve or the sympathetic chain according to the Fukurawa et $\mathrm{al}^{34}$ criteria. In schwannomas of the vagus nerve, the schwannoma grew between the common carotid artery and the IJV or between the ICA and the IJV, resulting in an increase in the distance between the artery and vein (separation). In schwannomas of the cervical sympathetic chain, no separation was observed between the IJV and the common carotid artery or ICA. 


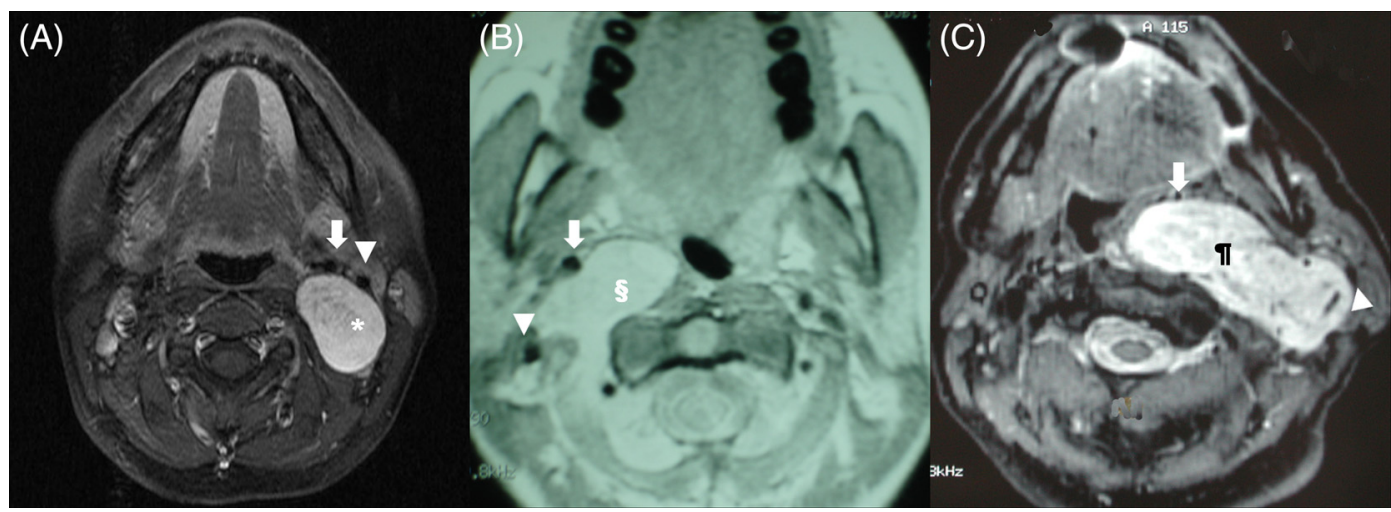

FIGURE 1 Retrostyloid space tumors. A, Axial T1-enhanced MRI shows a sympathetic schwannoma (*); and B, proton density axial sequence MRI shows a vagal schwannoma (§). Both tumors displace the ICA (arrow) and the IJV (arrowhead) laterally and demonstrate homogeneous enhancement during venous phase. Separation between the ICA and IJV can be seen when the tumor originates in the vagus nerve. C, Axial T2 with fat saturation shows a vagal paraganglioma (II). Diffusely enhancing mass adjacent to the skull base and centered high in the retrostyloid space. It displaces the ICA anteromedially (arrow) and IJV (arrowhead) [Color figure can be viewed at wileyonlinelibrary.com]

\section{9 | CT SCAN}

Information obtained from this study includes the location of a tumor in either the prestyloid or retrostyloid compartments, the presence or absence of a fat plane between the deep lobe of the parotid for a prestyloid mass, and degree of contrast enhancement. CT can demonstrate bony involvement and calcification within lesions. Bone invasion by malignant tumors can be seen, whereas bone erosion may occur by benign and (slowly growing) malignant tumors.

Schwannomas enhance because of the extravascular accumulation of contrast while a paraganglioma is a hypervascular mass.

If a retrostyloid mass is found or if malignancy is suspected, an MRI should be obtained.

\section{0 | MRI}

MRI is the first choice in the evaluation of parapharyngeal masses. It is able to better outline the position of the great vessels relative to the lesion, to delineate soft tissue and to demonstrate intracranial extension. The relationship between the mass and the ICA can be more clearly seen with MRI than with CT scan.

There are characteristic appearances of different tumors on MRI scan. Pleomorphic adenomas have low signal intensity on T1 images and high on T2 images and displace the ICA posteriorly. Schwannomas are isointense or hypointense on T1 images, with intense enhancement with gadolinium, and have higher signal intensity on T2 images like pleomorphic adenomas but displace the carotid anteromedially and may show cystic degeneration. Paragangliomas have a characteristic "salt and pepper" appearance on T2-weighted images because of flow voids. Flow voids are also typically observed in arteriovenous malformations.

\section{1 | ANGIOGRAPHY}

Selective preoperative angiography is usually recommended for large vagal and jugular paragangliomas, carotid body tumors, and other enhancing, vascular lesions. ${ }^{22}$ This study can demonstrate the relationship of the tumor to the great vessels and distinguish between neurogenic and vascular lesions. Angiography can be diagnostic of some lesions. Carotid body tumors cause splaying at the bifurcation resulting in the "lyre" sign. For the majority of jugular and vagal paragangliomas, preoperative embolization is recommended because of the difficulty that can be encountered in obtaining proximal and distal vascular control prior to tumor manipulation. However, there are conflicting data on the benefit of embolization in carotid body tumors and it may not be necessary. ${ }^{35}$ Moreover, carotid artery balloon occlusion tests

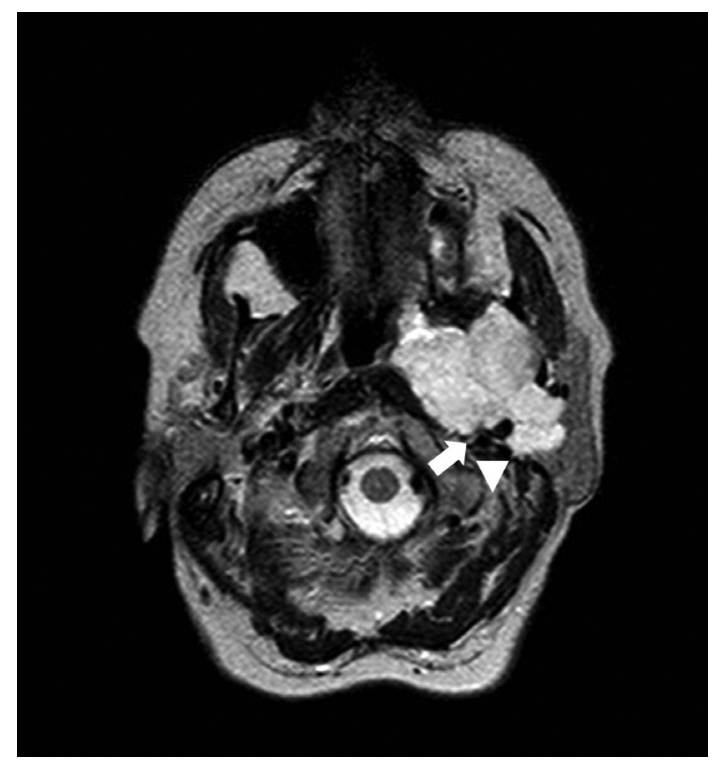

FIGURE 2 Prestyloid space tumor. Axial T2 MRI shows a pleomorphic adenoma of the deep parotid lobe (*) bulging to the prestyloid PPS. Note posterolateral displacement of the ICA and IJV 
should be performed if ICA infiltration is suspected or if there is the possibility of ICA sacrifice. ${ }^{6,29,30}$ In arteriovenous malformations, preoperative angiography with embolization is used to decrease blood loss during surgical resection.

CT angiography or MR angiography can be used for vascular mapping and to define the relationship of the tumor to the vessels and can define the competence of the circle of Willis anatomy and its potential for contralateral intracranial carotid blood flow.

\section{2 | MANAGEMENT}

The most widely used treatment for these tumors is surgical resection. ${ }^{36}$ Riffat et al ${ }^{2}$ report that $95 \%$ of the 1143 patients included in their study were treated by surgical resection. As most tumors are benign, complete surgical resection without causing additional major functional and aesthetic sequelae to the patient is the primary goal of surgery. Most prestyloid lesions can usually be treated safely because potential postoperative morbidity is low. Nevertheless, neurovascular complications are more likely in the surgical treatment of retrostyloid lesions, particularly in the case of vagal paraganglioma. Thus, in a systematic review on vagal paragangliomas, the vagal nerve was functionally preserved in only 11 of 254 surgically treated patients $(4.3 \%) .{ }^{37}$ As a consequence, not all patients should be operated on and surgery will not be indicated if the risks of surgery outweigh those of nonsurgical treatment or a "wait and see" policy. Elderly patients with asymptomatic benign tumors and patients with slow-growing benign tumors or neurogenic lesions, which are at high risk of cranial nerve damage if they are operated, should be managed with caution, and surgery should be avoided if it is expected to cause iatrogenic morbidity. A gradual loss of nerve function is usually better tolerated than sudden loss as a result of surgery, so observation or delayed removal is recommended in patients with normal neural function. Also, for some paragangliomas that are not functioning, a primary nonsurgical approach is often recommended. ${ }^{37}$

Patients with unresectable lesions, extended malignant lesions, and with ICA involvement, who have failed the balloon occlusion test, may not be suitable for surgery. Moreover, those patients with pre-existing contralateral deficits of the vagal and hypoglossal nerves may not be suitable for surgery because of the risk of bilateral deficits causing problems with swallowing and the airway. In these cases, radiotherapy is usually the primary modality of treatment. The same can be said of those vagal paraganglioma or vagal neuromas that experience appreciable growth during follow-up, as tumor control, major complication rates, and the number of cranial nerve palsies after treatment are significantly lower in radiotherapy than in surgical series. ${ }^{37}$
Adjuvant radiotherapy should be used in patients with malignancies, in those patients with potentially aggressive neoplasms in which wide surgical margins cannot be obtained, and in patients with incomplete resections. Despite this, malignant tumors present high recurrence rates and poor prognosis.

\section{3 | SURGERY}

Surgery of the PPS is a great challenge. Various approaches to the PPS have been described. ${ }^{29,30}$ All approaches can be used separately or in combination to obtain better exposure and resection of tumors. The choice of surgical approach is based on tumor size, location, histopathology, vascularity, superior extent and relationship to critical neurovascular structures, and the skull base, as well as host characteristics. An appropriate approach should allow wide enough exposure of the tumor for achieving complete resection and manage the eventual complications, with minimal aesthetic and functional morbidity. ${ }^{38}$ It is mandatory to preserve the integrity of the capsule (or pseudocapsule) to avoid tumor spillage. The surgeon's skills and experience are crucial for choosing the optimal approach because each one has advantages and limitations. Accordingly, more-experienced surgeons can perform more limited approaches to remove large tumors. Prasad et $\mathrm{al}^{9}$ has proposed an algorithm for the selection of appropriate surgical approaches in the management of PPS tumors. Table 2 describes the main approaches used and their indications.

In general, large tumors, highly vascularized lesions especially in close proximity to the skull base or neurovascular bundle, as well as malignancies usually require wider access. Tumors spanning the superior portion of the PPS can be completely removed through a skull base approach. To remove a large tumor in the middle and inferior portion of the PPS, a transparotid approach is the most suitable. Finally, a tumor in the inferior portion of the PPS is best accessed through a transcervical approach. ${ }^{39}$ However, the vast majority of benign tumors of the prestyloid space, regardless of their superior extension, can be resected by a transcervical, transparotid, or combined approach.

The most widely used surgical approach is the transcervical approach (Figure 3). ${ }^{10,16,29,30,40,41}$ Riffat et al ${ }^{2}$ report that in up to $48 \%$ of the 686 cases undergoing surgery, a transcervical approach was used. This approach allows to a satisfactory exposure of tumors and permits a good visualization of the cranial nerves and the control of the great vessels around them and avoids jeopardizing the facial nerve. This approach is used especially when the tumors (benign and malignant) are located in the inferior portion of the PPS, between the carotid sheath and pharyngeal constrictor muscles and when they do not displace the parotid gland laterally. The main limitation of this approach is the poor exposure of the medial and superior aspects of PPS and the 
TABLE 2 Main surgical approaches ${ }^{\mathrm{a}}$

\begin{tabular}{|c|c|c|}
\hline Approach & Indications & Surgical suggestions \\
\hline Transcervical & $\begin{array}{l}\text { Tumors (benign and malignant) located in the middle and } \\
\text { inferior portion of the PPS and benign tumors adjacent to } \\
\text { the skull base }\end{array}$ & $\begin{array}{l}\text {-The posterior belly of the digastric Mzuscle may be resected } \\
\text {-The extra-temporal facial nerve may be identified if necessary } \\
\text {-The styloid process may be transected }\end{array}$ \\
\hline Cervico-parotid & $\begin{array}{l}\text { Deep lobe parotid tumors and tumors involving the facial } \\
\text { nerve and tumors located in the upper portion of the PPS }\end{array}$ & $\begin{array}{l}\text {-In addition to transcervical approach } \\
\text {-Parotidectomy with preservation of the facial nerve }\end{array}$ \\
\hline Mandibular split ${ }^{\mathrm{b}}$ & $\begin{array}{l}\text { Selected malignant, recurrent or large tumors involving } \\
\text { ICA and adjacent to the skull base }\end{array}$ & -The inferior alveolar nerve should be preserved \\
\hline $\begin{array}{l}\text { Transcervical- } \\
\text { transmastoid } \\
\text { approach }\end{array}$ & Tumors of the upper PPS with a limited posterior extension & $\begin{array}{l}\text {-In addition to transcervical approach } \\
\text {-The mastoid tip is removed } \\
\text {-The facial nerve is left in its canal } \\
\text {-An infralabyrinthine dissection can be performed to expose the } \\
\text { sigmoid sinus and the jugular bulb to control the most inferior part } \\
\text { of the tumor }\end{array}$ \\
\hline $\begin{array}{l}\text { Infratemporal } \\
\text { fossa approaches } \\
\text { types A, B, or D }\end{array}$ & $\begin{array}{l}\text { Tumors involving the skull base or jugular foramen, } \\
\text { extending into the infratemporal fossa, or with significant } \\
\text { intracranial extension } \\
\text {-Type A: Tumors of the upper PPS with extension to the } \\
\text { vertical tract of the ICA } \\
\text {-Type B: Tumors of the upper PPS with an antero-medial } \\
\text {-Typension with respect to ICA } \\
\text { extension with respect to ICA }\end{array}$ & $\begin{array}{l}\text {-Type A: Anterior transposition of the facial nerve is performed to } \\
\text { provide optimal exposure of the jugular foramen and to allow } \\
\text { control over the distal parapharyngeal ICA up to the vertical petrous } \\
\text { portion and concurrent removal of small intradural tumor } \\
\text { extensions } \\
\text {-Type B: The facial nerve is identified and left in situ without any } \\
\text { manipulation; this approach provided access to the vertical and } \\
\text { horizontal portions of the petrous ICA, petrous apex, and mid to } \\
\text { lower clivus. } \\
\text {-Type D: Preauricular incision with a plane of dissection anterior to } \\
\text { the horizontal petrous ICA and the eustachian tube giving access to } \\
\text { the nasopharynx, the pterygopalatine Fossa, and the anterosuperior } \\
\text { PPS }\end{array}$ \\
\hline Transoral & Selected small benign tumors of the prestyloid space & $\begin{array}{l}\text {-Endoscope-assisted resection } \\
\text {-Transoral robotic resection }\end{array}$ \\
\hline
\end{tabular}

${ }^{\text {a }}$ Different approaches can be combined according to tumor characteristics and surgical skills.

${ }^{\mathrm{b}}$ Currently, transmandibular approaches have been minimized.

limited working space, with insufficient exposure of tumors approaching the base of the skull. ${ }^{42}$ For this reason, some surgeons combine this approach with other approaches, specially the transoral approach. A transverse incision at the level of the hyoid bone with either removal or displacement medially of the submandibular gland is performed. An incision is made in the posterior fascia of the submandibular gland and the digastric muscle and stylohyoid and hyoglossus muscles can be released from the hyoid bone, which can be resected partially. To increase the exposure, the styloid process may be cut at its origin along with Ryolan's bundle and the posterior belly of the digastric and the stylomandibular ligament can be divided, obtaining a better exposure of the upper portion of the PPS. ${ }^{4,43}$ Delicate dissection proceeds upward to reach the upper pole of the mass and, finally, tumors may often be bluntly dissected. If necessary, this approach can be extended with a mandibulotomy, transparotid, or transmastoid approaches.

An isolated transparotid approach or combined with a transcervical approach may be indicated if lesions are in close proximity to the facial nerve, including deep lobe parotid tumors extended to the PPS and minor salivary gland tumors (Figure 4) ${ }^{5,41}$ This approach is also appropriated for retrostyloid tumors located in the mid and upper portion of
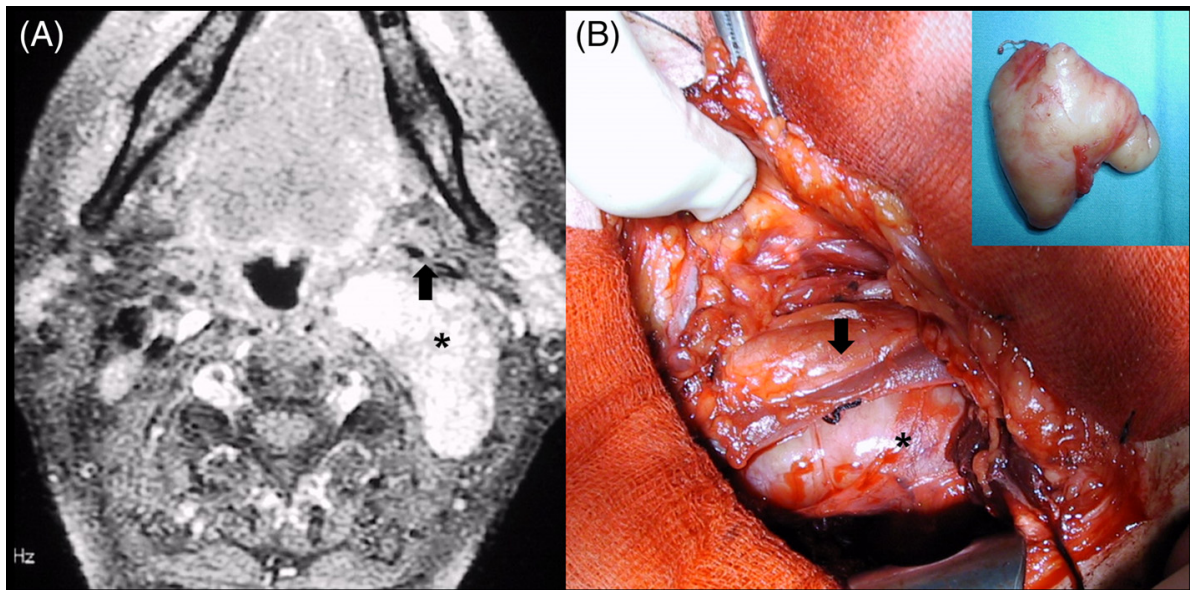

FIGURE 3 A, Diffusion-weighted imaging MRI shows a sympathetic schwannoma (*) tumor displacing the great vessels (arrow) anteriorly. B, This tumor was removed by a transcervical approach. Postoperative specimen with intact capsule (inset) [Color figure can be viewed at wileyonlinelibrary.com] 


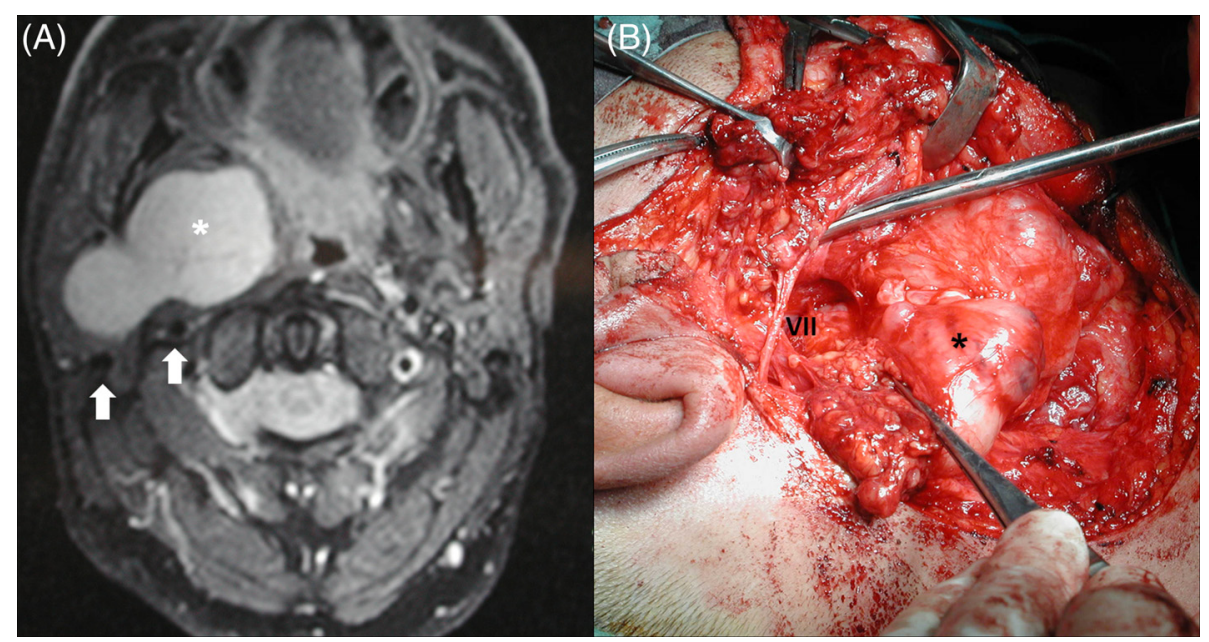

FIGURE 4 A, Axial T2 MRI shows the posterior displacement of the vessels (arrow) by a large pleomorphic adenoma $(*)$. B, This tumor $(*)$ was removed through a transcervical-transparotid approach, with preservation of the facial nerve (VII) [Color figure can be viewed at wileyonlinelibrary.com]

the PPS. The cervical approach is combined with a parotid approach by using a parotidectomy incision in front of the ear. This allows identification of the facial nerve trunk and lower division of the facial nerve, as well as exposing the ICA, jugular vein, and cranial nerves. An essential surgical step is prognathic dislocation of the mandible, following stylomandibular ligament and styloid muscle division, which would be favored by a nasal intubation. This can widen the exposure by more than $50 \%{ }^{44}$

Intraoperative monitoring facilitates the identification of the facial nerve and reduces the risk of unintended lesions, even when limiting surgical access to a purely transcervical route for aesthetic reasons. ${ }^{36}$ Parotid tissue resection is not always necessary, leaving the superficial parotid in place is aesthetically beneficial.

Currently, performing a mandibulotomy has few indications and in expert hands can be avoided in most cases. $^{29,30,45}$ It is required in $<10 \%$ of patients, including those with malignant, recurrent, or large tumors requiring a wide exposure, especially when there are concerns about the potential involvement of great cervical vessels. ${ }^{2,3,15,46}$ This procedure requires a delay in oral nutrition and may necessitate a tracheostomy as a result of the risk of postsurgical airway obstruction. Moreover, it carries the potential for a mandibular malunion, loss of dentition, and temporomandibular joint dysfunction. Mandibulotomy may be indicated for selected patients. Tumors located in the upper portion of the PPS and lesions that require distal control of the ICA or extensive exposure of the skull base are also candidates. Mandibulotomy of the body (median or paramedian), ramus, or the angle should preserve the inferior alveolar nerve as well as the hypoglossal and the lingual nerves although at risk in this approach. Some authors perform a non-lipsplitting mandibulotomy omitting the procedure of lower lip-splitting incision to improve the aesthetic results and to decrease the functional morbidities of the lower lip. ${ }^{47-50}$

An infratemporal fossa approach type A, B, or D may be used for tumors involving the skull base or jugular foramen, extending into the infratemporal fossa or with significant intracranial extension (Figure 5). ${ }^{9,51}$ Tumors with invasion of the PPS and the infratemporal fossa with extension to the floor of the middle cranial fossa can be removed by means of the preauricular subtemporal approach with low morbidity. ${ }^{52}$ Adequate ICA management is essential when planning surgical treatment for PPS lesions, especially in the presence of a limited working space and if there is a close relationship between the tumor and the ICA. If the tumor surrounds the ICA for more than half of its circumference, if there is

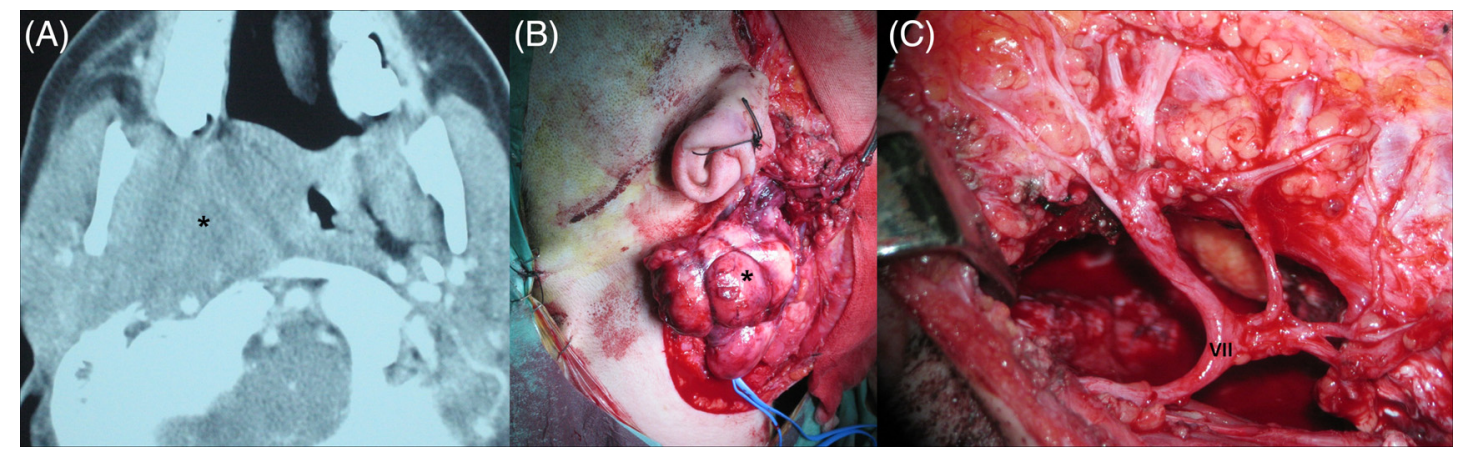

FIGURE 5 A, Axial CT shows a malignant fibrous histiocytoma (*) removed by an infratemporal fossa approach (B). C, Large, deep space left after resection of a tumor with preservation of the facial nerve (VII) [Color figure can be viewed at wileyonlinelibrary.com] 
evidence of stenosis, in cases of previous treatment (radiotherapy and surgery), if a single ipsilateral ICA is identified, and in glomus tumors, patients should be considered at risk. Subadventitial dissection or stenting of ICA gives a chance for complete tumor removal with arterial preservation, ${ }^{9,53}$ but in benign tumors, the disadvantages outweigh the advantages. For all tumors in which a risk for ICA damage and the need for shunting exists, surgeons' comfort can be improved by the use of near-infrared cerebral oximetry to monitor brain oxygenation. ${ }^{54-56}$ Carotid artery sacrifice and reconstruction should be avoided, although acceptable complication rates are reported in highly selected head and neck squamous cell carcinoma patients. ${ }^{57}$

Some years ago, transoral approaches were contraindicated but nowadays are advocated by some authors for selected small benign lesions of the prestyloid space presenting as an oropharyngeal and avascular mass and those not palpable in the neck or parotid. ${ }^{4,16,28,58}$ Problems with this approach are the limited exposure and the lack of control of the neck great vessels and the cranial nerves and, hence, possibility of neurovascular injury. An increased risk of tumor rupture or incomplete removal and contamination of the surgical field from saliva, with an increased risk of infections and wound dehiscence are other criticisms. Nevertheless some reports confirm the feasibility of the transoral route with few cases of tumor rupture or recurrence provided that a careful evaluation of indications and potential drawbacks is made before considering this approach, especially in salivary tumors. ${ }^{59-61}$

Minimally invasive approaches have been advocated to minimize surgical morbidity while claiming complete PPS tumor resection. In general, the use of endoscopic approaches has not been standardized and should be used only in selected cases and performed by highly skilled surgeons. ${ }^{62-65}$ Wang et $\mathrm{al}^{66}$ have reported that although PPS tumors may be completely removed by both external and transoral endoscopic approaches, the latter has the advantages of reduced blood loss and postoperative pain level and preservation of facial cosmetic. Similar results have been reported by Fan et al. ${ }^{67}$ Endoscope-assisted transoral resection provides a wider view, reducing the risks of neurovascular injury or capsule rupture and allowing resection of large tumors ${ }^{64,65}$; those tumors surrounded major vascular structures or with large lateral extension are not suitable. Endoscopy may also be used to overcome some of the limitations of external conventional approaches. ${ }^{12}$ It may be useful to visualize and dissect structures surrounding the tumor especially in the upper PPS, when reaching the skull base. ${ }^{68}$ Furthermore, endoscopy provides an excellent visualization of areas beyond the line of direct sight and enables confirmation of adequate hemostasis and the absence of residual tumor before closure. A variant of this technique is the minimally invasive video-assisted transcervical approach, which has shown to be safe and feasible for selected benign and malignant PPS tumors. ${ }^{69}$ Nevertheless, the use of endoscopic approaches has not been standardized and should be used only in selected cases and performed by highly skilled surgeons experienced in this approach.

Transnasal endoscopic access by means of a transpterygoid approach allows access to the upper part of the PPS. ${ }^{32,70}$ Wasano et $\mathrm{al}^{71}$ have described the modified endoscopic transnasal-transmaxillary-transpterygoid approach, in which the surgical corridor to the PPS consists of the maxillary sinus, submucous tunnel under the lateral nasal wall, and the space created by removing the pterygoid process. This deep region has traditionally been approached through open lateral or anterior approaches, which are associated with several significant complications. ${ }^{72-74}$ Endoscopic approaches may provide the surgeon with a minimally invasive and safe approach to radically resect selected tumors involving the upper PPS and thus reduce the needs for lateral approach or mandibulotomy. ${ }^{75}$ Further studies are needed to validate the reproducibility and efficacy of this technique. In addition, the consequences of creating a large sinonasal cavity are not negligible.

The use of transoral robotic surgery (TORS) has recently been attempted for the treatment of these tumors. ${ }^{76-78}$ Visual magnification and the precision of robotic instruments help the delicate dissection and avoidance of tumor fragmentation. ${ }^{14}$ Nevertheless, some authors have reported that capsule disruption may occur but with no obvious impact on the recurrence rate or the need for a transcervical conversion. ${ }^{14,76,77}$ TORS candidates are patients with adequate exposure of the oropharynx and whose preoperative assessment revealed a well-circumscribed neoplasm with lateral displacement of the ICA and clear cleavage plane from neurovascular bundle. ${ }^{14,79}$ TORS extends the advantages of the transoral conventional approach, allowing for the management of larger tumors. TORS may be used in both pre- and retrostyloid tumors and either benign or malignant cases. Boyce et $\mathrm{al}^{77}$ have reported the successful removal of 17 PPS tumors that ranged from 2 to $80 \mathrm{~cm}^{3}$, only two of them requiring a complementary cervical incision to assist with tumor removal. The far lateral and superior areas of the PPS, which required transcervical assistance, are inaccessible by this technique. ${ }^{77}$ Some authors have combined the use of endoscopy with TORS ${ }^{80}$; transcervical endoscopy is used for circumferential separation of the tumor from the neurovascular structures of the skull base, and then, after the tumor is separated, it is removed en bloc, via TORS. This approach could be utilized for the removal of large benign tumors, or small tumors located high at the skull base. Approaching PPS tumors by this approach should be reserved to very experienced transoral robotic surgeons.

Microdebrider-assisted volume reduction may be an elegant adjunct to facilitate resection in certain situations. ${ }^{81,82}$ Certain PPS schwannomas can be addressed by using this technique via a purely transcervical or transoral approaches; 
for vagal schwannomas, neuromonitoring can be combined to maximize nerve function preservation. Progressive debulking of the tumor allows its upper portion to be visualized and a better delineation of its relationships with surrounding structures, facilitating a safe resection through a limited cervical incision. The main disadvantage of this technique in PPS neurogenic tumors is its inability to preserve nerve function as the entire nerve is resected together with the tumor capsule. Nevertheless, intracapsular enucleation of schwannomas, avoiding damage to the surrounding nerve fibers, may be an option to achieve a functional preservation, ${ }^{83-85}$ although late recurrences have been described. ${ }^{86}$ Unlike neurogenic tumors, that have a thick capsule and a low risk of recurrence, in salivary tumors, capsule rupture may be associated with tumor spillage and elevated risk of recurrence. Therefore, caution should be taken with this technique and it does not seem suitable for salivary gland tumors. Both techniques may be combined with endoscopic or robot-assisted approaches.

\section{4 | NONSURGICAL MANAGEMENT}

In some cases of patients who are poor surgical candidates, who fail balloon occlusion, are elderly, have unresectable lesions, or have benign slow-growing tumors that would require sacrifice of multiple cranial nerves, surgery may not be the only option or the treatment of choice. Other options include observation and radiation.

Of important note, especially for paraganglioma, an initial "wait and scan" policy is recommendable in many patients. This policy was promoted in the Netherlands decades ago, following the observation in 108 patients that no growth occurred in more than half of the patients. Comparing surgical patients to observed patients, survival was equal but complications went two times greater in the surgical arm. ${ }^{87}$ This has been corroborated in other settings. Langerman et $\mathrm{al}^{3}$ documented that in 43 patients: $20 \%$ of tumors showed regression, $42 \%$ remained stable in size, while only $38 \%$ grew at mean $2 \mathrm{~mm} / \mathrm{y} .{ }^{88}$ This "wait and scan" policy can also be applied on radiologically benign neurogenic retrostyloid lesions such as schwannomas.

Given the rarity of the condition, there are no randomized controlled trials yet to compare surgery with radiotherapy for PPS lesions. However, in some tumors, the usefulness of radiotherapy has been demonstrated. The first on the list are large and clinically apparent paragangliomas and schwannomas when incomplete resection and, in particular, impairment of cranial nerves are expected if treated surgically. In such cases, radiotherapy is a valid or even preferred option. ${ }^{37,89}$ To abolish growth potential of these lesions, rather low radiation doses are sufficient. Indeed, no dose higher than 45 Gy showed any advantage in term of local control. In such scenario, radiotherapy usually induces cessation of further growth of the lesion or reduction in its size, rather than complete eradication of tumor, which is the goal of surgical intervention. Furthermore, side effects are insignificant when doses below 50 Gy and modern radiation techniques (intensity modulated or stereotactic) are used. Although radiation is not curable for paragangliomas, that means that the tumor persists, there is no growth, or progressive neurological involvement in up to $96 \%-100 \%$ of cases. ${ }^{37,90,91}$

Similar considerations apply to pleomorphic adenoma, when symptomatic and inoperable or in cases presented with multinodular and/or multiple recurrent tumors. ${ }^{92}$ Although the cure of large tumors with radiotherapy is less likely, radiation proved to be effective in postoperative setting, which was demonstrated in several retrospective series. However, selection of patients for radiotherapy after incomplete surgery in attempt to prevent further recurrences of a benign tumor must be weighed against patient's age, possibility for additional surgery, and the risk of malignant transformation. The latter increases with time and with the number of recurrences. Fractionated proton beam radiotherapy to 45-50 Gy has been recommended, although the use of neutron radiotherapy to treat recurrent pleomorphic adenoma has also been reported. ${ }^{93}$ Although observation is a fair option for elderly or medically unfit patients or those with small lesions.

\section{5 | COMPLICATIONS AND OUTCOMES}

Complications related to surgery are not very common if performed by expert surgeons. Nevertheless, potential complications should be explained to patients prior to surgery. Malignant tumors and neurogenic lesions have the great risk of injury.

Overall, the most common complications are cranial nerve injuries. ${ }^{13}$ The vagal nerve is the most commonly affected, mainly in retrostyloid tumors. Its injury results in vocal cord palsy but mainly a severe pharyngeal palsy, causing potentially very severe alterations in phonation and swallowing. These patients, if a spontaneous compensation does not occur, may require treatment with speech therapy and rehabilitation of swallowing. Not infrequently, a medialization thyroplasty or intracordal injection may be necessary. This may be done during tumor removal surgery if the nerve is intentionally sacrificed. Performing the thyroplasty concomitant to the vagus nerve resection offers better results (voice and swallowing) compared when it is done in a delayed way. ${ }^{94}$ The facial nerve may also be injured in prestyloid tumors and repair techniques may be required.

The first bite syndrome ${ }^{95}$ is the major complaint after otherwise uncomplicated surgery of the PPS. It is described as an acute and intense pain in the parotid region caused with the first bite of each meal. It is related to damage to sympathetic innervation of the parotid gland. Botulinum toxin A injection into the affected parotid gland produces a 
decrease in the severity of symptoms. It is a safe and viable noninvasive treatment for this difficult to treat condition and may lead to permanent resolution of symptoms in some patients. Other complications include, Claude Bernard Horner syndrome ${ }^{14}$ and the dysfunction of temporomandibular junction. Hematoma, infections (phlegmone and abscess formation), and trismus may also be observed. Hemorrhage resulting from vascular injury is hazardous but rare.

\section{6 | CONCLUSION}

Tumors of the PPS arise in an anatomically complex region of the body. Furthermore, the low incidence of such tumors and their histological diversity have hampered diagnosis and management and prevented the accumulation of clinical experience at individual institutions. Nevertheless, the clinical management of these tumors has improved as a result of advances in imaging and surgical techniques. The clinical presentation of these tumors can be subtle. Therefore, radiological imaging provides critical information for diagnosis and surgical planning. The goal of treatment is complete tumor resection while limiting the aesthetic and functional sequelae. Surgery of PPS tumors has always been challenging because of the deep location, which limits visualization and manipulation, and the presence of important neurovascular structures that require adequate exposure and careful management to avoid complications. The transcervical approach is the most widely used, although the use of endoscopes and the refinement of surgical techniques made more limited approaches possible. Further long-term evaluation is needed to define patient selection and the role of endoscopy and TORS for PPS neoplasms.

\section{ORCID}

Fernando López (DD https://orcid.org/0000-0001-7019-9746

Vincent Vander Poorten (D) https://orcid.org/0000-0003-1341-829X

Primož Strojan (D) https://orcid.org/0000-0002-0445-112X

Ehab Y. Hanna (iD https://orcid.org/0000-0003-3241-2440

Juan Pablo Rodrigo (D) https://orcid.org/0000-0003-3063-0890

Remco de Bree (D) https://orcid.org/0000-0001-7128-5814

Robert P. Takes (D) https://orcid.org/0000-0003-4784-0499

Alfio Ferlito (D) https://orcid.org/0000-0002-8247-8002

\section{REFERENCES}

1. Maheshwar AA, Kim EY, Pensak ML, Keller JT. Roof of the parapharyngeal space: defining its boundaries and clinical implications. Ann Otol Rhinol Laryngol. 2004;113:283-288.

2. Riffat F, Dwivedi RC, Palme C, Fish B, Jani P. A systematic review of 1143 parapharyngeal space tumors reported over 20 years. Oral Oncol. 2014;50: 421-430.

3. Kuet ML, Kasbekar AV, Masterson L, Jani P. Management of tumors arising from the parapharyngeal space: a systematic review of 1,293 cases reported over 25 years. Laryngoscope. 2015;125:1372-1381.

4. Carrau RL, Myers EN, Johnson JT. Management of tumors arising in the parapharyngeal space. Laryngoscope. 1990;100:583-589.
5. Locketz GD, Horowitz G, Abu-Ghanem S, et al. Histopathologic classification of parapharyngeal space tumors: a case series and review of the literature. Eur Arch Otorhinolaryngol. 2016;273:727-734.

6. Olsen KD. Tumors and surgery of the parapharyngeal space. Laryngoscope. 1994;104:1-28.

7. Curtin HD. Separation of the masticator space from the parapharyngeal space. Radiology. 1987;163:195-204.

8. Stambuk HE, Patel SG. Imaging of the parapharyngeal space. Otolaryngol Clin North Am. 2008;41:77-101.

9. Prasad SC, Piccirillo E, Chovanec M, La Melia C, De Donato G, Sanna M. Lateral skull base approaches in the management of benign parapharyngeal space tumors. Auris Nasus Larynx. 2015;42:189-198.

10. Sun F, Yan Y, Wei D, et al. Surgical management of primary parapharyngeal space tumors in 103 patients at a single institution. Acta Otolaryngol. 2018;138:85-89.

11. Iglesias-Moreno MC, López-Salcedo MA, Gómez-Serrano M, GimenoHernández J, Poch-Broto J. Parapharyngeal space tumors: fifty-one cases managed in a single tertiary care center. Acta Otolaryngol. 2016;136:298-303.

12. Shi $X$, Tao L, Li X, et al. Surgical management of primary parapharyngeal space tumors: a 10-year review. Acta Otolaryngol. 2017;137:656-651.

13. Grilli G, Suaárez V, Muñoz MG, Costales M, Llorente JL. Parapharyngeal space primary tumours. Acta Otorrinolaringol Esp. 2017;68:138-144

14. Chu F, Tagliabue M, Giugliano G, Calabrese L, Preda L, Ansarin M. From transmandibular to transoral robotic approach for parapharyngeal space tumors. Am J Otolaryngol. 2017;38:375-379.

15. Papadogeorgakis N, Petsinis V, Goutzanis L, Kostakis G, Alexandridis C. Parapharyngeal space tumors: surgical approaches in a series of 13 cases. Int J Oral Maxillofac Surg. 2010;39:243-250.

16. Dimitrijevic MV, Jesic SD, Mikic AA, Arsovic NA, Tomanovic NR. Parapharyngeal space tumors: 61 case reviews. Int J Oral Maxillofac Surg. 2010; 39:983-989.

17. John DG, Carlin WV, Brown MJ. Tumours of the parapharyngeal space. $J R$ Coll Surg Edinb. 1988;33:56-60.

18. Dankle SK. Neoplasms of the parapharyngeal space. Ear Nose Throat J. 1987;66:491-501.

19. Colen TY, Mihm FG, Mason TP, Roberson JB. Catecholamine-secreting paragangliomas: recent progress in diagnosis and perioperative management. Skull Base. 2009;19:377-385.

20. Mendenhall WM, Amdur RJ, Vaysberg M, Mendenhall CM, Werning JW. Head and neck paragangliomas. Head Neck. 2011;33:1530-1534.

21. Sato $Y$, Imanishi $Y$, Tomita $T$, et al. Clinical diagnosis and treatment outcomes for parapharyngeal space schwannomas: a single-institution review of 21 cases. Head Neck. 2018;40:569-576.

22. Som PM, Biller HF, Lawson W, Sacher M, Lanzieri CF. Parapharyngeal space masses: an updated protocol based upon 104 cases. Radiology. 1984; 153:149-156.

23. Allison RS, Van der Waal I, Snow GB. Parapharyngeal tumours: a review of 23 cases. Clin Otolaryngol Allied Sci. 1989;14:199-203.

24. Shoss SM, Donovan DT, Alford BR. Tumors of the parapharyngeal space. Arch Otolaryngol. 1985;111:753-757.

25. Maran AG, Mackenzie IJ, Murray JA. The parapharyngeal space. J Laryngol Otol. 1984;98:371-380.

26. Luna-Ortiz K, Navarrete-Aleman JE, Granados-Garcia M, HerreraGomez A. Primary parapharyngeal space tumors in a Mexican cancer center. Otolaryngol Head Neck Surg. 2005;132:587-591.

27. Shahab R, Heliwell T, Jones AS. How we do it: a series of 114 primary pharyngeal space neoplasms. Clin Otolaryngol. 2005;30:364-367.

28. Bozza F, Vigili MG, Ruscito P, Marzetti A, Marzetti F. Surgical management of parapharyngeal space tumours: results of 10-year follow-up. Acta Otorhinolaryngol Ital. 2009;29:10-15.

29. Oliai BR, Sheth $S$, Burroughs FH, Ali SZ. "Parapharyngeal space" tumors: a cytopathological study of 24 cases on fine-needle aspiration. Diagn Cytopathol. 2005;32:11-15.

30. Bradley PJ, Bradley PT, Olsen KD. Update on the management of parapharyngeal tumours. Curr Opin Otolaryngol Head Neck Surg. 2011;19:92-98.

31. Gupta A, Chazen JL, Phillips CD. Imaging evaluation of the parapharyngeal space. Otolaryngol Clin North Am. 2012;45:1223-1232.

32. Dallan I, Lenzi R, Bignami M, et al. Endoscopic transnasal anatomy of the infratemporal fossa and upper parapharyngeal regions: correlations with traditional perspectives and surgical implications. Minim Invasive Neurosurg. 2010;53:261-269. 
33. Muraz E, Delemazure AS, Mourrain-Langlois E, Bourget K, Malard O, Frampas E. Peripharyngeal space tumors: can magnetic resonance and multidetector-row computed tomography help predict location, malignancy and tumor type? Diagn Interv Imaging. 2016;97:617-625.

34. Furukawa M, Furukawa MK, Katoh K, Tsukuda M. Differentiation between schwannoma of the vagus nerve and schwannoma of the cervical sympathetic chain by imaging diagnosis. Laryngoscope. 1996;106:1548-1552.

35. Moore MG, Netterville JL, Mendenhall WM, Isaacson B, Nussenbaum B. Head and neck paragangliomas: an update on evaluation and management. Otolaryngol Head Neck Surg. 2016;154:597-605.

36. Paderno A, Piazza C, Nicolai P. Recent advances in surgical management of parapharyngeal space tumors. Curr Opin Otolaryngol Head Neck Surg. 2015;23:83-90.

37. Suárez C, Rodrigo JP, Bödeker CC, et al. Jugular and vagal paragangliomas: a systematic study on management with surgery and radiotherapy. Head Neck. 2013;35:1195-1204.

38. Infante-Cossio P, González-Cardero E, González-Pérez LM, LeopoldoRodado M, Garcia-Perla A, Esteban F. Management of parapharyngeal giant pleomorphic adenoma. Oral Maxillofac Surg. 2011;15:211-216.

39. Kanzaki S, Nameki H. Standardised method of selecting surgical approaches to benign parapharyngeal space turnouts, based on pre-operative images. J Laryngol Otol. 2008;122:628-634.

40. Cohen SM, Burkey BB, Netterville JL. Surgical management of parapharyngeal space masses. Head Neck. 2005;27:669-675.

41. Cassoni A, Terenzi V, Della Monaca M, et al. Parapharyngeal space benign tumors: our experience. J Craniomaxillofac Surg. 2014;42:101-105.

42. Som PM, Biller HF, Lawson W. Tumors of the parapharyngeal space: preoperative evaluation, diagnosis and surgical approaches. Ann Otol Rhinol Laryngol. 1981;90:3-15.

43. Basaran B, Polat P, Unsaler S, Ulusan M, Aslan I, Hafiz G. Parapharyngeal space tumours: the efficiency of a transcervical approach without mandibulotomy through review of 44 cases. Acta Otorhinolaryngol Ital. 2014;34:310-316

44. Carrau RL, Johnson JT, Myers EN. Management of tumors of the parapharyngeal space. Oncology (Williston Park). 1997;11:633-640. discussion 640-2.

45. Vikatmaa P, Makitie AA, Railo M, Törnwall J, Albäck A, Lepäntalo M. Midline mandibulotomy and interposition grafting for lesions involving the internal carotid artery below the skull base. J Vasc Surg. 2009;49:86-92.

46. Chang SS, Goldenberg D, Koch WM. Transcervical approach to benign parapharyngeal space tumors. Ann Otol Rhinol Laryngol. 2012;121: 620-624.

47. Baek CH, Lee SW, Jeong HS. New modification of the mandibulotomy approach without lip splitting. Head Neck. 2006;28:580-586.

48. Cantù G, Bimbi G, Colombo S, et al. Lipsplitting in transmandibular resections: is it really necessary? Oral Oncol. 2006;42:619-624.

49. Smith GI, Brennan PA, Webb AA, Ilankovan V. Vertical ramus osteotomy combined with a parasymphyseal mandibulotomy for improved access to the parapharyngeal space. Head Neck. 2003;25:1000-1003.

50. Teng MS, Genden EM, Buchbinder D. Urken ML subcutaneous mandibulotomy: a new surgical access for large tumors of the parapharyngeal space. Laryngoscope. 2003;113:1893-1897.

51. Ohue S, Fukushima T, Kumon Y, Ohnishi T, Friedman AH. Preauricular transzygomatic anterior infratemporal fossa approach for tumors in or around infratemporal fossa lesions. Neurosurg Rev. 2012;35:583-592.

52. Llorente JL, Nazar G, Cabanillas R, Fernández de León R, Suárez C. Subtemporal preauricular approach in the management of infratemporal and nasopharyngeal tumours. J Otolaryngol. 2006;35:173-179.

53. Sanna M, Piazza P, De Donato G, Menozzi R, Falcioni M. Combined endovascular-surgical management of the internal carotid artery in complex tympanojugular paragangliomas. Skull Base. 2009;19:26-42.

54. Dujovny M, Slavin KV, Hernandez G, Geremia GK, Ausman JI. Use of cerebral oximetry to monitor brain oxygenation reserves for skull base surgery. Skull Base Surg. 1994;4:117-121.

55. Jonsson M, Lindstrom $D$, Wanhainen A, Djavani GK, Gillgren P. Near infrared spectroscopy as a predictor for shunt requirement during carotid endarterectomy. Eur J Vasc Endovasc Surg. 2017;53:783-791.

56. Radak D, Sotirovic V, Obradovic M, Isenovic ER. Practical use of nearinfrared spectroscopy in carotid surgery. Angiology. 2014;65:769-772.

57. Bäck LJJ, Aro K, Tapiovaara L, et al. Sacrifice and extracranial reconstruction of the common or internal carotid arteryin advanced head and neck carcinoma: review and meta-analysis. Head Neck. 2018;40:1305-1320. https:// doi.org/10.1002/hed.25093.
58. Hussain A, Ah-See KW, Shakeel M. Trans-oral resection of large parapharyngeal space tumours. Eur Arch Otorhinolaryngol. 2014;271:575-582.

59. Eisele DW, Richmon JD. Contemporary evaluation and management of parapharyngeal space neoplasms. J Laryngol Otol. 2013;127:550-555.

60. Ducic Y, Oxford L, Pontius AT. Transoral approach to the superomedial parapharyngeal space. Otolaryngol Head Neck Surg. 2006;134:466-470.

61. Betka J, Chovanec M, Klozar J, et al. Transoral and combined transoral transcervical approach in the surgery of parapharyngeal tumors. Eur Arch Otorhinolaryngol. 2010;267:765-772.

62. Dallan I, Fiacchini G, Turri-Zanoni M, et al. Endoscopic-assisted transoraltranspharyngeal approach to parapharyngeal space and infratemporal fossa: focus on feasibility and lessons learned. Eur Arch Otorhinolaryngol. 2016; 273:3965-3972.

63. Dallan I, Seccia V, Muscatello L, et al. Transoral endoscopic anatomy of the parapharyngeal space: a step-by-step logical approach with surgical considerations. Head Neck. 2011;33:557-561.

64. Chen WL, Wang YY, Zhang DM, Huang ZQ. Endoscopy-assisted transoral resection of large benign parapharyngeal space tumors. Br J Oral Maxillofac Surg. 2014;52:970-973

65. Iseri M, Ozturk M, Kara A, Ucar S, Aydin O, Keskin G. Endoscope-assisted transoral approach to parapharyngeal space tumors. Head Neck. 2015;37: 243-248.

66. Wang X, Gong S, Lu Y, Pan X, Luo X, Sun H. Endoscopy-assisted transoral resection of parapharyngeal space tumors: a retrospective analysis. Cell Biochem Biophys. 2015;71:1157-1163.

67. Fan S, Lin SG, Zhang HQ, et al. A comparative study of the endoscopyassisted transoral approach versus external approaches for the resection of large benign parapharyngeal space tumors. Oral Surg Oral Med Oral Pathol Oral Radiol. 2017;123:157-162.

68. Beswick DM, Vaezi A, Caicedo-Granados E, Duvvuri U. Minimally invasive surgery for parapharyngeal space tumors. Laryngoscope. 2012;122: 1072-1078.

69. Pilolli F, Giordano L, Galli A, Bussi M. Parapharyngeal space tumours: video-assisted minimally invasive transcervical approach. Acta Otorhinolaryngol Ital. 2016;36:259-264.

70. Van Rompaey J, Suruliraj A, Carrau R, Panizza B, Solares CA. Access to the parapharyngeal space: an anatomical study comparing the endoscopic and open approaches. Laryngoscope. 2013;123:2378-2382.

71. Wasano K, Yamamoto S, Tomisato S, Kawasaki T, Ogawa K. Modified endoscopic transnasal-transmaxillary-transpterygoid approach to parapharyngeal space tumor resection. Head Neck. 2016;38:933-938.

72. Sekhar LN, Schramm VL Jr, Jones NF. Subtemporal-preauricular infratemporal fossa approach to large lateral and posterior cranial base neoplasms. J Neurosurg. 1987;67:488-499.

73. Janecka IP. Classification of facial translocation approach to the skull base. Otolaryngol Head Neck Surg. 1995;112:579-585.

74. Fisch U. The infratemporal fossa approach for nasopharyngeal tumors. Laryngoscope. 1983;93:36-44.

75. Battaglia P, Turri-Zanoni M, Dallan I, et al. Endoscopic endonasal transpterygoid transmaxillary approach to the infratemporal and upper parapharyngeal tumors. Otolaryngol Head Neck Surg. 2014;150:696-702.

76. Chan JY, Tsang RK, Eisele DW, Richmon JD. Transoral robotic surgery of the parapharyngeal space: a case series and systematic review. Head Neck. 2015;37:293-298

77. Boyce BJ, Curry JM, Luginbuhl A, Cognetti DM. Transoral robotic approach to parapharyngeal space tumors: case series and technical limitations. Laryngoscope. 2016;126:1776-1782.

78. De Virgilio A, Park YM, Kim WS, Byeon HK, Lee SY, Kim SH. Transoral robotic surgery for the resection of parapharyngeal tumour: our experience in ten patients. Clin Otolaryngol. 2012;37:483-488.

79. Ansarin M, Tagliabue M, Chu F, Zorzi S, Proh M, Preda L. Transoral robotic surgery in retrostyloid parapharyngeal space schwannomas. Case Rep Otolaryngol. 2014;2014:296025.

80. Duek I, Amit M, Sviri GE, Gil Z. Combined endoscopic transcervicaltransoral robotic approach for resection of parapharyngeal space tumors. Head Neck. 2017;39:786-790.

81. Chennupati SK, Schipor I, Mirza N. Microdebrider decompression of schwannoma: a novel method of excising a neck mass. Laryngoscope. 2006; 116:2086-2088 
82. Nicolai P, Paderno A, Farina D, Piazza C. Microdebrider cavitation and transcervical removal of parapharyngeal schwannomas approaching the skull base. Eur Arch Otorhinolaryngol. 2014;271:3305-3311.

83. de Araujo CE, Ramos DM, Moyses RA, Durazzo MD, Cernea CR, Ferraz AR. Neck nerve trunks schwannomas: clinical features and postoperative neurologic outcome. Laryngoscope. 2008;118:1579-1582.

84. Battoo AJ, Sheikh ZA, Thankappan K, et al. Nerve-sparing subcapsular resection of head and neck schwannomas: technique evaluation and literature review. J Laryngol Otol. 2013;127:685-690.

85. Kim SH, Kim NH, Kim KR, Lee JH, Choi HS. Schwannoma in head and neck: preoperative imaging study and intracapsular enucleation for functional nerve preservation. Yonsei Med J. 2010;51:938-942.

86. Torossian JM, Beziat JL, Abou Chebel N, Devouassoux-Shisheboran M, Fischer G. Extracranial cephalic schwannomas: a series of 15 patients. J Craniofac Surg. 1999;10:389-394.

87. van der Mey AG, Frijns JH, Cornelisse CJ, et al. Does intervention improve the natural course of glomus tumors? A series of 108 patients seen in a 32-year period. Ann Otol Rhinol Laryngol. 1992;101:635-642.

88. Langerman A, Athavale SM, Rangarajan SV, Sinard RJ, Netterville JL. Natural history of cervical paragangliomas: outcomes of observation of 43 patients. Arch Otolaryngol Head Neck Surg. 2012;138:341-345.

89. Anderson BM, Khuntia D, Bentzen SM, et al. Single institution experience treating 104 vestibular schwannomas with fractionated stereotactic radiation therapy or stereotactic radiosurgery. J Neurooncol. 2014; 116:187-193.

90. Hinerman RW, Amdur RJ, Morris CG, Kirwan J, Mendenhall WM. Definitive radiotherapy in the management of paragangliomas arising in the head and neck: a 35-year experience. Head Neck. 2008;30:14311438 .

91. Verniers DA, Keus RB, Schouwenburg PF, Bartelink H. Radiation therapy, an important mode of treatment for head and neck chemodectomas. Eur $J$ Cancer. 1992;28:1028-1033.

92. Witt RL, Eisele DW, Morton RP, Nicolai P, Poorten VV, Zbären P. Etiology and management of recurrent parotid pleomorphic adenoma. Laryngoscope. 2015; $125: 888-893$.

93. Douglas JG, Einck J, Austin-Seymour M, Koh WJ, Laramore GE. Neutron radiotherapy for recurrent pleomorphic adenomas of major salivary glands. Head Neck. 2001;23:1037-1042.

94. Mom T, Filaire M, Advenier D, et al. Concomitant type I thyroplasty and thoracic operations for lung cancer: preventing respiratory complications associated with vagus or recurrent laryngeal nerve injury. J Thorac Cardiovasc Surg. 2001;121:642-648.

95. Costales-Marcos M, López Álvarez F, Fernández-Vañes L, Gómez J, Llorente JL. Treatment of the first bite syndrome. Acta Otorrinolaringol Esp. 2017;68:284-288.

How to cite this article: López F, Suárez C, Vander Poorten V, et al. Contemporary management of primary parapharyngeal space tumors. Head \& Neck. 2019;41:522-535. https://doi.org/10.1002/hed.25439 